\title{
Narrative review of sleep and pulmonary hypertension
}

\author{
Bacon Jenny Louise ${ }^{1}$, Fleming Carys ${ }^{1}$, Marino Philip $^{2}$ \\ ${ }^{1}$ Surrey and Sussex Healthcare NHS Trust, Redhill, UK; ${ }^{2}$ Guy's and St Thomas' NHS Foundation Trust, London, UK \\ Contributions: (I) Conception and design: None; (II) Administrative support: F Carys; (III) Provision of study materials or patients: None; (IV) \\ Collection and assembly of data: BJ Louise; (V) Data analysis and interpretation: BJ Louise, M Philip; (VI) Manuscript writing: All authors; (VII) \\ Final approval of manuscript: All authors. \\ Correspondence to: Bacon Jenny Louise. Surrey and Sussex Healthcare NHS Trust, East Surrey Hospital, Redhill, Surrey RH1 5RH, UK. \\ Email: jb901@doctors.org.uk.
}

\begin{abstract}
Pulmonary hypertension $(\mathrm{PH})$ is a condition of raised pulmonary artery pressure (PAP), which may be secondary to a number of causes, one of which is sleep disordered breathing (SDB). When PH complicates SDB, it carries a significant burden of morbidity and mortality due to the risk of progression to right ventricular failure over time. This narrative review will cover the definition and classification of $\mathrm{PH}$, and explore the epidemiology of $\mathrm{PH}$ in SDB. The mechanisms by which the two conditions are linked will be reviewed. Repetitive hypoxia with or without hypercapnia alongside frequent arousals can result in important metabolic and pulmonary vascular consequences for the left and right heart. MEDLINE was used to search for all relevant articles and abstracts published from January 1960 to October 2019 inclusive (in all languages). Current best practice in the investigation and management of PH complicating SDB will be reviewed. Important diagnostic investigations and when to consider and screen further for $\mathrm{PH}$ in patients with SDB will be discussed. Optimal disease management must include control of SDB with therapy. Additional treatment options will be reviewed. Areas for further research will be highlighted.
\end{abstract}

Keywords: Pulmonary hypertension (PH); pulmonary heart disease; sleep apnoea syndromes; sleep apnoea; obstructive; hypoventilation

Submitted May 30, 2020. Accepted for publication Aug 17, 2020.

doi: 10.21037 /jtd-cus-2020-004

View this article at: http://dx.doi.org/10.21037/jtd-cus-2020-004

\section{Introduction}

Pulmonary hypertension $(\mathrm{PH})$ is a condition of raised pulmonary artery pressure (PAP) defined at right heart catheterisation. A considerable number of conditions are known to be associated with $\mathrm{PH}$, one of which is sleep disordered breathing (SDB). The presence of $\mathrm{PH}$ with SDB offers a much worse prognosis compared to SDB alone, in terms of morbidity and mortality due to the risk of progression to right ventricular failure over time, making it an important condition to recognise (1-5).

The current epidemiology, pathophysiology and management of $\mathrm{PH}$ in SDB will be explored in this narrative review.

MEDLINE was used to search for all articles and abstracts published from January 1960 to October 2019 inclusive (in all languages) that contained the following key words or terms: Sleep disordered breathing; Sleep Apnoea Syndromes; Obstructive Sleep Apnoea; Obesity Hypoventilation syndrome; Pulmonary Hypertension; Pulmonary Arterial Hypertension.

We present the following article/case in accordance with the Narrative Review Checklist (available at http://dx. doi. org/10. 21037/jtd-cus-2020-004).

\section{PH: definition \& classification}

$\mathrm{PH}$ is defined by haemodynamic values obtained at right heart catheterisation. The pressure, flow and resistance in the pulmonary circulation can be measured, as well as the contribution from left atrial pressure. An elevation in mean PAP $\geq 25 \mathrm{mmHg}$ historically defined the condition 
Table 1 Haemodynamic definition of pulmonary hypertension (6)

\begin{tabular}{lccc}
\hline Definition & $\begin{array}{c}\text { Mean pulmonary artery pressure } \\
(\mathrm{mmHg})\end{array}$ & $\begin{array}{c}\text { Pulmonary arterial wedge } \\
\text { pressure }(\mathrm{mmHg})\end{array}$ & $\begin{array}{c}\text { Pulmonary vascular resistance } \\
\text { (Wood Units) }\end{array}$ \\
\hline Pre-capillary PH & $>20$ & $\leq 15$ & $\geq 3$ \\
Isolated post-capillary PH & $>20$ & $>15$ & $>3$ \\
Combined pre- and post-capillary PH & $>20$ & $>15$ & $\geq 3$ \\
\hline
\end{tabular}

$\mathrm{PH}$, pulmonary hypertension.

but recently this has been reduced to a value exceeding $20 \mathrm{mmHg}$, to identify a sizeable population of at-risk patients (6).

In some patients, a significantly elevated pulmonary arterial wedge pressure (PAWP) at right heart catheterisation identifies that an elevation in PAP is transmitted from the left heart, termed post-capillary PH. By assessing the transpulmonary gradient (mean PAP PAWP) and dividing this by cardiac output, the pulmonary vascular resistance is defined. When there is a significant elevation in pulmonary vascular resistance, in conjunction with a normal PAWP, this indicates true pulmonary vascular disease (pre-capillary $\mathrm{PH}$ ) as opposed to a passive elevation in back pressure from the left heart alone. However, in many patients with left heart disease there is a reactive phenotype where the pulmonary vascular resistance is elevated in addition to the PAP and PAWP (combined preand post-capillary $\mathrm{PH}$ ) (see Table 1).

The heterogeneous aetiologies that can lead to $\mathrm{PH}$ are classified into 5 distinct clinical groups according to current guidelines (Table 2). Patients with $\mathrm{PH}$ due to left heart disease fall within group 2 of the $\mathrm{PH}$ classification. Those cases associated with hypoventilation and hypoxia related to SDB are classified into group 3. PH may often be multifactorial with patients being classified into more than one group or subgroup.

\section{Epidemiology}

The estimated prevalence of $\mathrm{PH}$ in patients with SDB varies, reflecting differences in the diagnostic test used (i.e., transthoracic echocardiogram versus right heart catheterisation), referring centre (i.e., specialist sleep centre versus general respiratory clinic), and the time point of the natural history of the SDB. Patients with SDB often also have other associated cardiac comorbidities including left ventricular dysfunction, which can itself lead to $\mathrm{PH}$. The prevalence of $\mathrm{PH}$ in patients with obstructive sleep apnoea (OSA) even without overt heart or lung disease is likely as high as $31 \%$ (7).

The true prevalence of $\mathrm{PH}$ in obesity hypoventilation syndrome (OHS) or other conditions of hypoventilation is largely unknown. In 77 prospective patients with OHS, $71 \%$ of women and $62 \%$ of men had echocardiography suggestive of $\mathrm{PH}$ in the largest Canadian study (8). A German study performed the gold standard right heart catheterisation on 21 of 64 patients with OHS. Seventeen patients had PH (81\%) of which $47 \%$ were mild $(<25 \mathrm{mmHg})$ and three had a significant contribution from left heart disease (9).

\section{Pathophysiology}

The mechanisms by which SDB is associated with the development of $\mathrm{PH}$ are detailed in Figure 1.

\section{Hypoxia}

Recurrent oxygen desaturation in OSA or hypoventilation leads to chronic intermittent hypoxia in patients with SDB. This increases inflammation and oxygen-derived free radical formation that in turn promotes the activation of pro-inflammatory transcription factors. Endothelial cell and leucocyte activation also occurs, together with increased expression of adhesion molecules and vascular endothelial growth factor, and the activation of "stress" genes that influence oxygen delivery, such as hypoxia inducible factor-1 (10). The expression of potent vasoconstrictors such as endothelin-1 and serotonin are also increased in a hypoxic environment (11). These pathways ultimately lead to hypoxic pulmonary vasoconstriction, pulmonary vascular remodelling, and endothelial dysfunction $(12,13)$. Significant differences in acute pulmonary vasoconstriction have been shown in different people and also different species (14-16). 
Table 2 Current pulmonary hypertension classification (6)

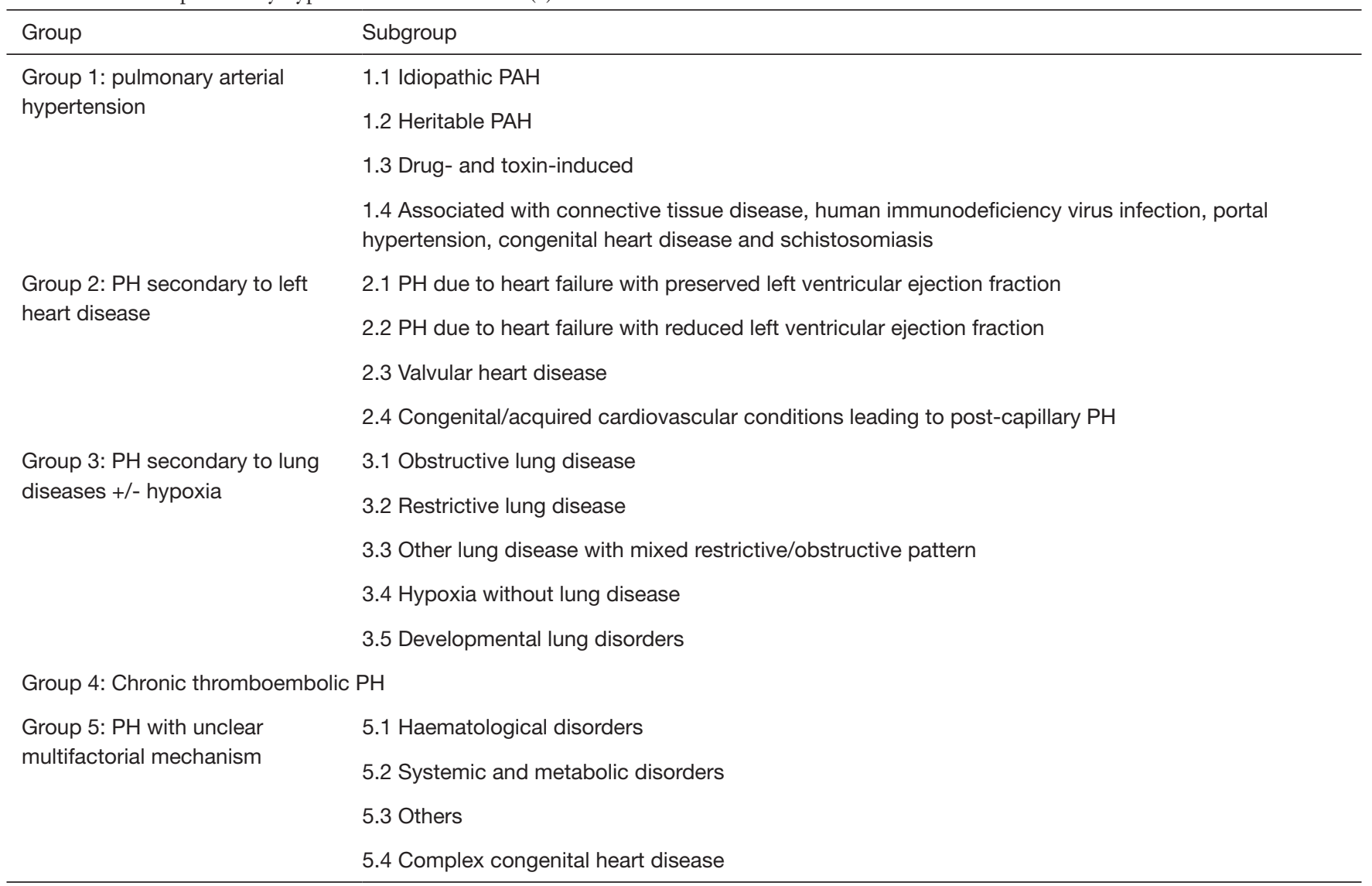

$\mathrm{PAH}$, pulmonary arterial hypertension; $\mathrm{PH}$, pulmonary hypertension.

\section{Hypercapnia}

The presence of an elevated carbon dioxide level and acidosis may further promote hypoxia-induced pulmonary vasoconstriction, however, not all patients with nocturnal hypoventilation and hypercapnia develop PH $(17,18)$.

\section{Negative intrathoracic pressure}

The repeated generation of an elevated negative intrathoracic pressure against an occluded upper airway, as occurs in OSA, may lead to increased venous return and excessive preload to the right ventricle (RV) during these apnoeas $(19,20)$. This can precipitate decompensation of the $\mathrm{RV}$ in the presence of $\mathrm{PH}$.

\section{Frequent arousals}

Reduced sleep quantity in conjunction with frequent arousals in SDB triggers increased inflammation, as evidenced by elevated interleukin-6, high-sensitivity C-reactive protein, and leucocyte counts (10). This may promote endothelial dysfunction and vascular remodelling as seen in the pulmonary arterial hypertension phenotype. Frequent arousals also stimulate the sympathetic nervous system and increase renin-angiotensin-aldosterone activity. Resistant systemic hypertension can arise and, if not appropriately managed, leave patients at risk of developing left heart disease, such as left ventricular systolic or diastolic dysfunction. Increased sympathetic activity may also precipitate arrhythmias that can cause acute decompensation in RV function in patients with $\mathrm{PH}$.

\section{Left heart disease}

SDB can induce refractory systemic hypertension through the combination of oxidative stress, endothelial dysfunction and increase in sympathetic tone. The presence of 


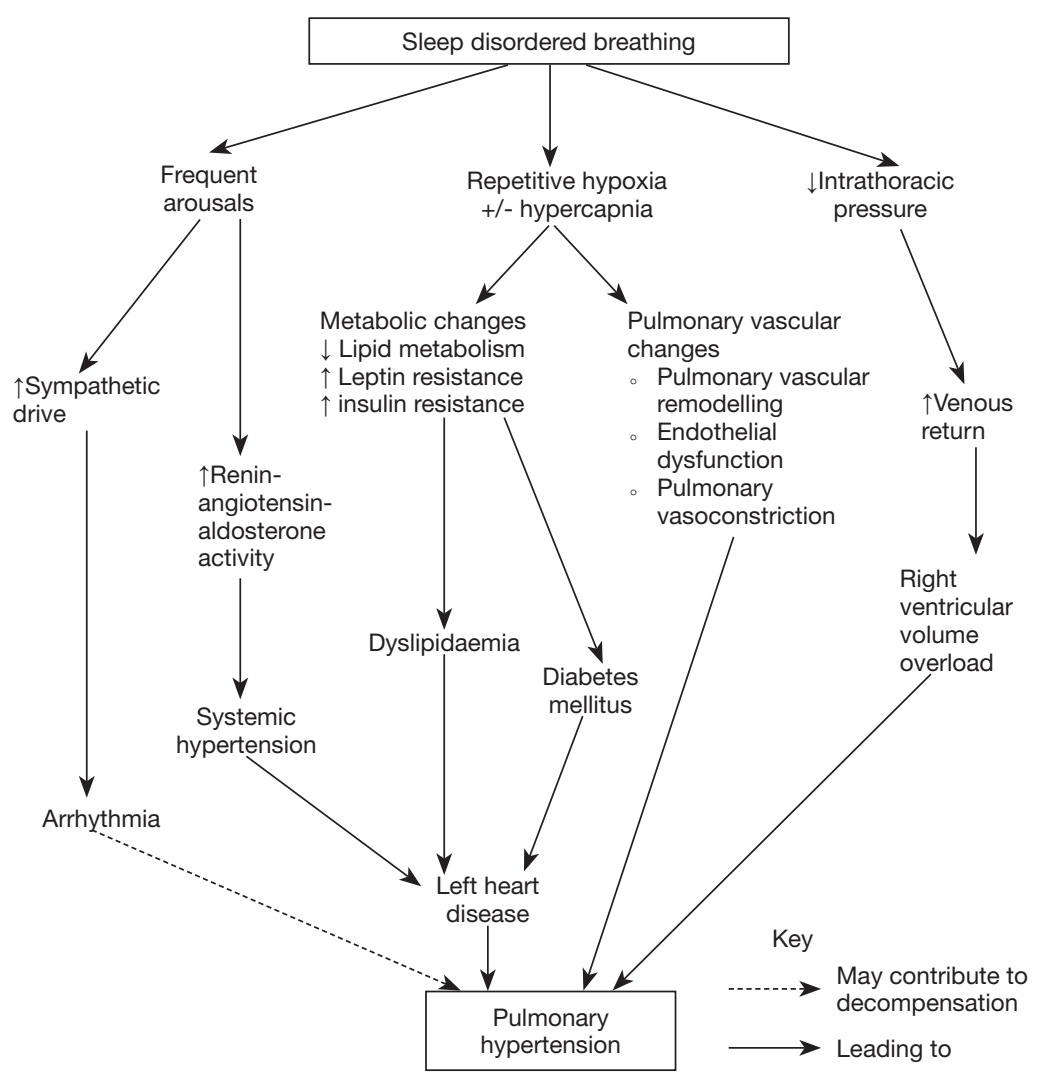

Figure 1 The pathophysiological changes that can result from sleep disordered breathing and contribute to the development or decompensation of pulmonary hypertension.

coexistent obesity, diabetes and metabolic syndrome in patients with SDB results in an increased cardiovascular risk, leading to a higher prevalence of left heart disease (21). As mentioned previously, any elevation in left atrial and/ or ventricular pressure may increase the PAP through passive transmission of this pressure to the pulmonary circulation (22).

OSA is also associated with left ventricular hypertrophy, even in the absence of hypertension, obesity, and diabetes $(23,24)$. Left ventricular hypertrophy appears to correlate with mean nocturnal oxygen saturation as an independent predictor of left ventricular mass and wall thickness $(25,26)$. One study over 18 years in 119 OSA patients showed a $1.3 \%$ independent decrease in left ventricular ejection fraction for every tenfold increase in the apnoea-hypopnoea index (AHI) $(25,27,28)$. In humans, left ventricular systolic dysfunction appears to arise after longer periods of OSA of over 10 years $(29,30)$.

Left atrial enlargement is an important sign, suggesting that an elevated left atrial pressure may be contributing to the development of PH. This was reported in $18 \%$ of newly diagnosed OSA patients (31), and was significantly more common amongst subjects with moderate-to-severe OSA (52\%) than patients with an AHI $<15$ (32).

Left ventricular diastolic dysfunction has been as prevalent in as many as $57 \%$ of patients with mild OSA in some studies (33), whilst in newly diagnosed patients, reports are lower at $23 \%$ (31). In severe disease the prevalence of left ventricular diastolic dysfunction may rise as high as $70 \%$.

\section{Obesity}

In addition to OHS, approximately $40 \%$ to $60 \%$ of cases of OSA are accredited to elevated body mass index, predisposing to upper airway collapse (10). The prevalence of $\mathrm{PH}$ in obese patients is higher than in the general population, with $5 \%$ of all individuals with a body mass index greater than $30 \mathrm{~kg} / \mathrm{m}^{2}$ having been shown to have some degree of PH (34). It has also been shown that 
isolated obesity in young adults is associated with subclinical abnormalities in RV structure and function, which are independent of the presence of OSA and its severity $(35,36)$. An autopsy study found histological features of pulmonary arterial and pulmonary venous hypertension in $72 \%$ of obese patients compared with only $26 \%$ and $6 \%$ respectively in non-obese controls (37).

\section{The $R V$}

The function of the RV is key with respect to prognosis and the development of symptoms in patients with $\mathrm{PH}$. The pulmonary circulation is normally a low resistance, low-pressure system, whilst the RV is a thin-walled and compliant structure that normally works against low afterload and has adapted for the changeable volumes it can encounter (8,38-40). RV hypertrophy may develop in response to a progressive rise in pulmonary vascular resistance and afterload over time. However, the RV has limited contractile reserve and will subsequently dilate, with decreasing contractile strength $(41,42)$. This in turn increases RV wall tension and oxygen demand, whilst decreasing perfusion, leading to the development of a vicious cycle that will ultimately result in $\mathrm{RV}$ failure. The contractile reserve of the $\mathrm{RV}$ is determined by a variety of factors that include the degree of re-modelling and fibrosis, as well as the severity and time course for the increase in afterload (41,43-45). A recent meta-analysis that included 25 case-control studies, totalling 1,503 patients with OSA and 796 healthy controls, looked at RV structure and function by transthoracic echocardiography. This highlighted considerable heterogeneity between studies but overall OSA patients had evidence of significant RV dilatation, increased wall thickening, and altered RV function compared to controls (46).

\section{Correlation with severity of disease}

There appears to be no correlation between the severity of OSA and the degree of PAP elevation (7,12,47-49). However, a correlation between severity of OSA and RV structure and function assessed by echocardiographic parameters has been shown [RV myocardial performance index (50-52), RV ejection fraction (51), tissue Dopplerderived tricuspid lateral annular systolic velocity (S') (53-55), tricuspid annular plane systolic excursion $(19,52), \mathrm{RV}$ internal diameter (53), RV wall thickness (52), and RV strain variables $(19,56,57)]$.

\section{Investigation of PH}

\section{Diagnostic assessment}

It is important not to assume that PH is solely attributable to SDB or other known pathologies. A detailed history and examination should focus on other potential causes as outlined in Table 2. A drug history should look for the use of agents implicated in the development of $\mathrm{PH}$, such as appetite suppressants, immunotherapies (e.g., tyrosine kinase inhibitors) and illicit drugs (e.g., methamphetamines). Risk factors for acute or chronic thromboembolic disease, including family history and, for example, splenectomy, should be identified. Features of connective tissue and/or chronic liver disease must also be explored.

Baseline investigations should include liver function, thyroid profile and human immunodeficiency virus (HIV) testing, and performing serological markers for connective tissue disease when appropriate. Biochemical markers such as B-type natriuretic peptide (BNP), N-terminal pro B-type natriuretic peptide (NT-proBNP) and troponin may aid initial assessment and monitoring of RV dysfunction, although they should be interpreted with caution as they may rise in other conditions such as left ventricular dysfunction or chronic renal disease.

An electrocardiogram may show features of right heart strain and is essential for uncovering any rhythm disturbance. A chest radiograph may help identify an overt lung or cardiac pathology.

Computerised Tomography (CT) provides a detailed assessment of the pulmonary vasculature, cardiac chambers and parenchymal lung disease. CT Pulmonary Angiography (CTPA) can detect both acute and chronic thromboembolic disease. Ventilation-Perfusion scanning when co-registered with CT may demonstrate more distal thrombus in those patients in whom CTPA is negative but there remains a high index of clinical suspicion. Pulmonary function testing will identify coexistent restrictive and obstructive lung disease, as well as demonstrating reduced gas transfer consistent with pulmonary vascular disease.

Echocardiography is a readily accessible and noninvasive test used to aid diagnosis, guide risk-stratification and monitor progress of $\mathrm{PH}$ patients. Echocardiography windows are often suboptimal in patients with SDB due to body habitus but an estimate of PAP, RV structure and function evaluation, and an assessment of inter-ventricular interaction is possible, in addition to detection of intra- 


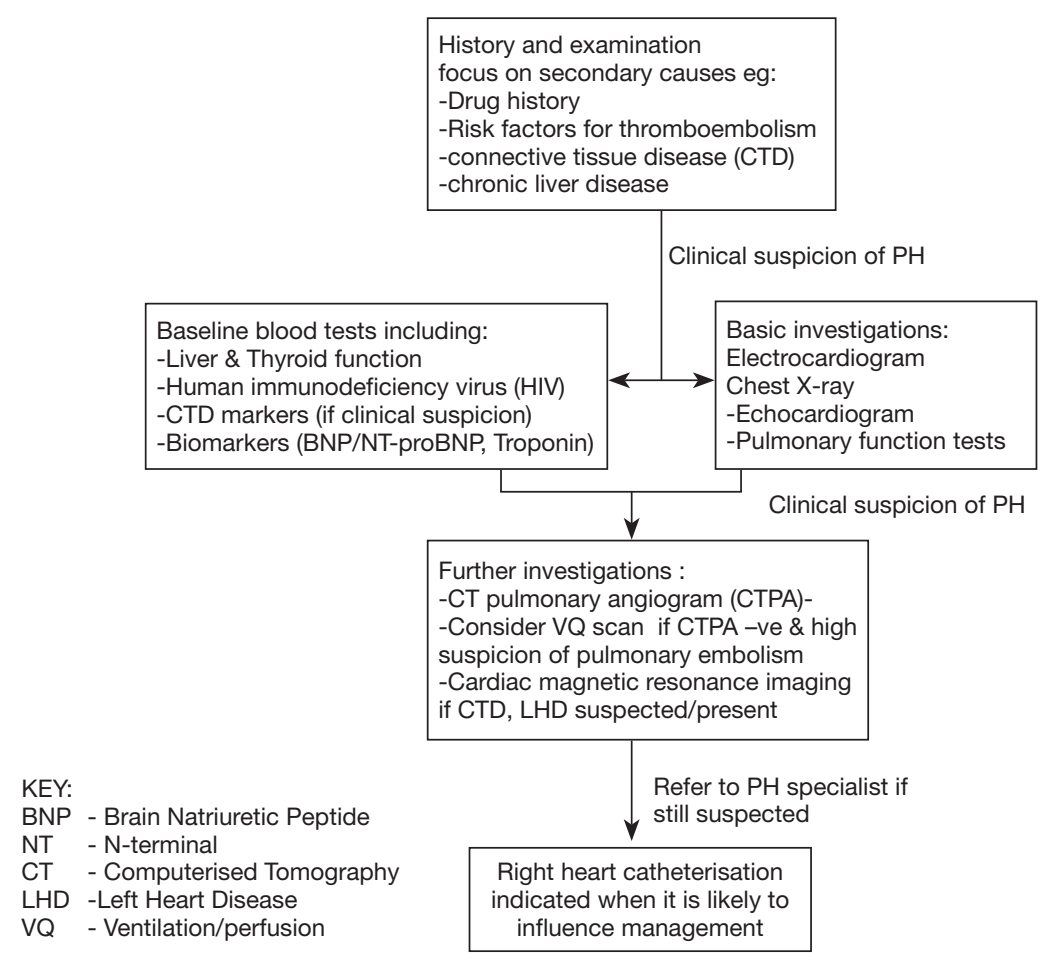

Figure 2 Investigation of $\mathrm{PH}$. PH, pulmonary hypertension.

cardiac shunts, and valvular or primary myocardial disease. Cardiac magnetic resonance imaging (MRI) is accurate and reproducible in the assessment of RV size, morphology and function, and in the non-invasive assessment of blood flow, including stroke volume, cardiac output, pulmonary arterial distensibility and right ventricular mass. However, MRI may not be feasible in the morbidly obese. Non-invasive modalities are excellent for serial assessment, however, for a definitive diagnosis right heart catheterisation is still required.

Although right heart catheterisation is required to formally diagnose $\mathrm{PH}$ it is an invasive procedure with inherent risks (58). Current $\mathrm{PH}$ guidelines with respect to $\mathrm{PH}$ in chronic hypoxia and lung disease state that right heart catheterisation is indicated when a patient's management will likely be influenced by the results (59). This may include any referral for transplantation (noting that raised body mass index is an important exclusion for lung transplant), inclusion in clinical trials or registries, treatment of unmasked left heart dysfunction, or compassionate use of therapy. The diagnostic pathway is summarised in Figure 2.

\section{Screening}

Detailed echocardiographic screening for subclinical heart failure and PH may potentially improve clinical outcomes in SDB patients through earlier diagnosis and by raising awareness concerning the clinical consequences of their sleep-disordered breathing. This could in turn promote patient adherence to both device therapy and lifestyle changes.

We advocate a detailed review of patient presentation and further investigation if there are disproportionate symptoms such as breathlessness, chest pain and pre-syncope, or a history and examination consistent with right heart failure.

Routine echocardiographic screening of patients with lone OSA is not currently undertaken but one should have a low threshold for this investigation. If $\mathrm{PH}$ is suspected we would routinely perform NT-proBNP as a biochemical marker to screen for cardiac pathology and further investigate as appropriate. A routine echocardiogram is performed for all patients with obesity hypoventilation to screen for the condition, due to the poor prognosis associated with the finding of $\mathrm{PH}$ and to guide management 
of the conditions.

\section{Treatment}

\section{$O S A$}

The first step in treatment is to correct overnight hypoxia using Continuous Positive Airway Pressure (CPAP), unless there is significant hypercapnia for which non-invasive ventilation (NIV) may be indicated. CPAP may reduce pulmonary vascular reactivity to hypoxia and improve pulmonary endothelial function, resulting in decreased PAPs (60).

A meta-analysis of 7 studies identified 222 OSA patients (AHI $>10$ events/hour, mean 58/hour) with confirmed $\mathrm{PH}$ (mean PAP $>25 \mathrm{mmHg}$ and normal PAWP excluding left heart disease) but without comorbid cardiothoracic disease (7). After a minimum of 3 months CPAP therapy ( $>4.5$ hours use per night) a mean drop in PAP of $13 \mathrm{mmHg}$ was observed. Of note, only one study utilised right heart catheterisation to confirm treatment effect, confirming a mean drop of $12 \mathrm{mmHg}$ in PAP (61). Other studies have included co-morbid conditions such as chronic obstructive pulmonary disease and left heart disease which can also cause PH. These patients may not improve with CPAP therapy and hence variations in PAP responses have been shown (62).

\section{OHS}

$\mathrm{PH}$ is often severe in OHS and commonly associated with RV failure and poor outcomes (63). A significant proportion of these patients present with $\mathrm{PH}(64,65)$.

The effect of treatment with NIV on $\mathrm{PH}$ in OHS patients has not been fully established to date $(9,63,64)$. One randomised controlled trial and two series showed near normalisation of pulmonary haemodynamics after 3-6 months with NIV (63-65). One further study on 14 patients with obesity-related hypercapnic respiratory failure reviewed echocardiography features of $\mathrm{PH}$ preand post-NIV treatment ( 6 patients with $>4$ hours adherence with therapy) and found no difference from baseline at 3 months (66). A positive treatment effect from NIV on the respiratory system was demonstrated by neural respiratory drive assessment despite there being no significant effect on the cardiovascular system in the short term.
It is not fully known why $\mathrm{PH}$ can persist despite optimal treatment with ventilation. These patients may represent a different clinical phenotype perhaps more in keeping with pulmonary arterial hypertension which does not respond to CPAP or NIV but in whom selective pulmonary vasodilator therapy may potentially be effective. It is also possible that further studies utilising right heart catheterisation would demonstrate residual $\mathrm{PH}$ being driven mostly by the left heart.

\section{General management}

It is important to ensure that any CPAP or NIV initiated is sufficient to prevent significant hypoxia overnight. Supplemental oxygen may sometimes be required overnight and hypoxic awake patients should be screened for the need for long term oxygen therapy. It should be noted that patients with impaired RV function may require higher oxygen levels to avoid tissue hypoxia (67). However, our current practice is to aim for oxygen saturation levels of $\geq 90 \%$ overnight and partial pressure of oxygen $>8 \mathrm{kPa}$ when awake at rest.

Fluid balance is key to symptom management and patients should be advised regarding appropriate fluid restriction. Diuretic therapy should be implemented if there are signs of RV failure or fluid retention. There is evidence that mineralocorticoid receptor antagonists improve left ventricular diastolic function in patients with heart failure with preserved ejection fraction despite no effect on allcause mortality or hospitalization (68).

Digoxin may be considered to improve symptoms of RV failure (69). It has been shown to improve cardiac output acutely in idiopathic pulmonary arterial hypertension, although its efficacy is unknown when administered chronically. It is also essential to identify and address any arrhythmias to prevent acute RV decompensation by achieving early restoration of sinus rhythm.

Iron supplementation should be considered in patients with confirmed deficiency to improve symptoms whilst concurrently investigating for a cause for their deficiency. Replacement appears to have favourable clinical effects even without anaemia and may be associated with reduced mortality (70-73).

Finally, patients should be counselled regarding their increased risk associated with surgery or pregnancy. Careful planning amongst professional teams and with the patient is required to pursue these options. 


\section{Summary}

There is an increased morbidity and mortality associated with the development of $\mathrm{PH}$ in patients with SDB. This underscores the need for early and effective treatment, which is primarily optimal ventilation with medical management of any associated RV failure. We currently have limited data on the true prevalence, mechanism and optimal management of these important co-existent pathologies, highlighting the need for further high-quality studies to address these issues.

\section{Acknowledgments}

Funding: None.

\section{Footnote}

Reporting Checklist: The authors have completed the Narrative Review Checklist. Available at http://dx.doi. org/10.21037/jtd-cus-2020-004

Provenance and Peer Review: This article was commissioned by the Guest Editor (Joerg Steier) for the series " $5^{\text {th }}$ Clinical Update Sleep" published in Fournal of Thoracic Disease. The article was sent for external peer review organized by the Guest Editor and the editorial office.

Conflicts of Interest: All authors have completed the ICMJE uniform disclosure form (available at http:// dx.doi.org/10.21037/jtd-cus-2020-004). The series " $5^{\text {th }}$ Clinical Update Sleep" was commissioned by the editorial office without any funding or sponsorship. BJL reports Meeting sponsorship from Actelion pharmaceuticals, outside the submitted work. MP reports grants from Janssen Pharmaceuticals, personal fees from Janssen Pharmaceuticals, other from Janssen Pharmaceuticals, personal fees from MSD/Bayer, other from MSD/Bayer Pharmaceuticals, other from GSK Pharmaceuticals, outside the submitted work. The authors have no other conflicts of interest to declare.

Ethical Statement: The authors are accountable for all aspects of the work in ensuring that questions related to the accuracy or integrity of any part of the work are appropriately investigated and resolved.

Open Access Statement: This is an Open Access article distributed in accordance with the Creative Commons Attribution-NonCommercial-NoDerivs 4.0 International License (CC BY-NC-ND 4.0), which permits the noncommercial replication and distribution of the article with the strict proviso that no changes or edits are made and the original work is properly cited (including links to both the formal publication through the relevant DOI and the license). See: https://creativecommons.org/licenses/by-nc-nd/4.0/.

\section{References}

1. Minai OA, Ricaurte B, Kaw R, et al. Frequency and impact of pulmonary hypertension in patients with obstructive sleep apnea syndrome. Am J Cardiol 2009;104:1300-6.

2. Berkowitz R, Alhaj E, Manchikalapudi RB, et al. Determinants of right ventricular failure in patients admitted with acute left heart failure. Congest Heart Fail 2010;16:243-8.

3. Priou P, Hamel JF, Person C, et al. Long-term outcome of noninvasive positive pressure ventilation for obesity hypoventilation syndrome. Chest 2010;138:84-90.

4. Castro-Añón O, Pérez de Llano LA, De la Fuente Sánchez $S$, et al. Obesity-hypoventilation syndrome: increased risk of death over sleep apnea syndrome. PLoS One 2015;10:e0117808.

5. Budweiser S, Riedl SG, Jörres RA, et al. Mortality and prognostic factors in patients with obesity-hypoventilation syndrome undergoing noninvasive ventilation. J Intern Med 2007;261:375-83.

6. Simonneau G, Montani D, Celermajer DS, et al. Haemodynamic definitions and updated clinical classification of pulmonary hypertension. Eur Respir J 2019;53:1801913.

7. Imran TF, Marya G, Spencer L, et al. Effect of continuous positive airway pressure treatment on pulmonary artery pressure in patients with isolated obstructive sleep apnea: a meta-analysis. Heart Fail Rev 2016;21:591-8.

8. Almeneessier AS, Nashwan SZ, Al-Shamiri MQ, et al. The prevalence of pulmonary hypertension in patients with obesity hypoventilation syndrome: a prospective observational study. J Thorac Dis 2017;9:779-88.

9. Kauppert CA, Dvorak I, Koller F, et al. Pulmonary hypertension in obesity-hypoventilation syndrome. Respir Med 2013;107:2061-70.

10. Cowie MR. Sleep apnea: state of the art. Trends Cardiovasc Med 2017;27:280-9.

11. Kholdani C, Fares WH, Mohsenin V. Pulmonary hypertension in obstructive sleep apnea: is it clinically 
significant? A critical analysis of the association and pathophysiology. Pulm Circ 2015;5:220-7.

12. Sajkov D, Wang T, Saunders NA, et al. Daytime pulmonary hemodynamics in patients with obstructive sleep apnea without lung disease. Am J Respir Crit Care Med 1999;159:1518-26.

13. Faller DV. Endothelial cell responses to hypoxic stress. Clin Exp Pharmacol Physiol 1999; 26:74-84.

14. Hawryłkiewicz I, Sliwiński P, Górecka D, et al. Pulmonary haemodynamics in patients with OSAS or an overlap syndrome. Monaldi Arch Chest Dis 2004;61:148-52.

15. Zieliński J. Effects of intermittent hypoxia on pulmonary haemodynamics: animal models versus studies in humans. Eur Respir J 2005;25:173-80.

16. Chaouat A, Weitzenblum E, Kessler R, et al. Sleep-related $\mathrm{O} 2$ desaturation and daytime pulmonary haemodynamics in COPD patients with mild hypoxaemia. Eur Respir J 1997;10:1730-5.

17. Lloyd Jr TC. Influence of blood $\mathrm{pH}$ on hypoxic pulmonary vasoconstriction. J Appl Physiol 1966;21:358-64.

18. McGuire M, Bradford A. Chronic intermittent hypercapnic hypoxia increases pulmonary arterial pressure and haematocrit in rats. Eur Respir J 2001;18:279-85.

19. Altekin RE, Karakas MS, Yanikoglu A, et al. Determination of right ventricular dysfunction using the speckle tracking echocardiography method in patients with obstructive sleep apnea. Cardiol J 2012;19:130-9.

20. Bradley TD, Hall MJ, Ando S, et al. Hemodynamic effects of simulated obstructive apneas in humans with and without heart failure. Chest 2001;119:1827-35.

21. Korcarz CE, Peppard PE, Young TB, et al. Effects of obstructive sleep apnea and obesity on cardiac remodeling: the Wisconsin sleep cohort study. Sleep 2016;39:1187-95.

22. Vachiéry JL, Tedford RJ, Rosenkranz S, et al. Pulmonary hypertension due to left heart disease. Eur Respir J 2019;53:1801897.

23. Dursunoglu D, Dursunoglu N, Evrengül H, et al. Impact of obstructive sleep apnoea on left ventricular mass and global function. Eur Respir J 2005;26:283-8.

24. Altekin RE, Yanikoglu A, Karakas MS, et al. Evaluation of subclinical left ventricular systolic dysfunction in patients with obstructive sleep apnea by automated function imaging method; an observational study. Anadolu Kardiyol Derg 2012;12:320-30.

25. Akyol S, Cortuk M, Baykan AO, et al. Biventricular myocardial performance is impaired in proportion to severity of obstructive sleep apnea. Tex Heart Inst J 2016;43:119-25.
26. Chami HA, Devereux RB, Gottdiener JS, et al. Left ventricular morphology and systolic function in sleepdisordered breathing: the Sleep Heart Health Study. Circulation 2008;117:2599-607.

27. Brooks D, Horner RL, Kozar LF, et al. Obstructive sleep apnea as a cause of systemic hypertension: evidence from a canine model. J Clin Invest 1997;99:106-9.

28. Parker JD, Brooks D, Kozar LF, et al. Acute and chronic effects of airway obstruction on canine left ventricular performance. Am J Respir Crit Care Med 1999;160:1888-96.

29. Yang SQ, Han LL, Dong XL, et al. Mal-effects of obstructive sleep apnea on the heart. Sleep Breath 2012;16:717-22.

30. Fung JW, Li TS, Choy DK, et al. Severe obstructive sleep apnea is associated with left ventricular diastolic dysfunction. Chest 2002;121:422-9.

31. Baguet JP, Barone-Rochette G, Levy P, et al. Left ventricular diastolic dysfunction is linked to severity of obstructive sleep apnoea. Eur Respir J 2010;36:1323-9.

32. Hjälm HH, Fu M, Hansson PO, et al. Association between left atrial enlargement and obstructive sleep apnea in a general population of 71-year-old men. J Sleep Res 2018;27:252-8.

33. Wachter R, Luthje L, Klemmstein D, et al. Impact of obstructive sleep apnoea on diastolic function. Eur Respir J 2013;41:376-83.

34. McQuillan BM, Picard MH, Leavitt M, et al. Clinical correlates and reference intervals for pulmonary artery systolic pressure among echocardiographically normal subjects. Circulation 2001;104:2797-802.

35. Sokmen A, Sokmen G, Acar G, et al. The impact of isolated obesity on right ventricular function in young adults. Arq Bras Cardiol 2013;101:160-8.

36. Wong CY, O'Moore-Sullivan T, Leano R, et al. Association of subclinical right ventricular dysfunction with obesity. J Am Coll Cardiol 2006;47:611-6.

37. Haque AK, Gadre S, Taylor J, et al. Pulmonary and cardiovascular complications of obesity: an autopsy study of 76 obese subjects. Arch Pathol Lab Med 2008;132:1397-404.

38. Haddad F, Doyle R, Murphy DJ, et al. Right ventricular function in cardiovascular disease, part II: pathophysiology, clinical importance, and management of right ventricular failure. Circulation 2008;117:1717-31.

39. Di Salvo TG. Pulmonary hypertension and right ventricular failure in left ventricular systolic dysfunction. Curr Opin Cardiol 2012;27:262-72. 
40. Segers VF, Brutsaert DL, De Keulenaer GW. Pulmonary hypertension and right heart failure in heart failure with preserved left ventricular ejection fraction: pathophysiology and natural history. Curr Opin Cardiol 2012;27:273-80.

41. Bogaard HJ, Abe K, Vonk Noordegraaf A, et al. The Right Ventricle Under Pressure: cellular and molecular mechanisms of right-heart failure in pulmonary hypertension. Chest 2009; 135:794-804.

42. Braunwald E, Bonow RO. Braunwald's heart disease: a textbook of cardiovascular medicine. 9th ed. Philadelphia: Elsevier Saunders, 2012.

43. Faber MJ, Dalinghaus M, Lankhuizen IM. Right and left ventricular function after chronic pulmonary artery banding in rats assessed with biventricular pressurevolume loops. Am J Physiol Heart Circ Physiol 2006;291:H1580-6.

44. Taraseviciene-Stewart L, Kasahara Y, Alger L, et al. Inhibition of the VEGF receptor 2 combined with chronic hypoxia causes cell death-dependent pulmonary endothelial cell proliferation and severe pulmonary hypertension. FASEB J 2001;15:427-38.

45. Haddad F, Vrtovec B, Ashley EA, et al. The concept of ventricular reserve in heart failure and pulmonary hypertension: an old metric that brings us one step closer in our quest for prediction. Curr Opin Cardiol 2011;26:123-31.

46. Maripov A, Mamazhakypov A, Sartmyrzaeva M, et al. Right ventricular remodelling and dysfunction in obstructive sleep apnea: a systematic review of the literature and meta-analysis. Can Respir J 2017;2017:1587865.

47. Sajkov D, Cowie RJ, Thornton AT, et al. Pulmonary hypertension and hypoxemia in obstructive sleep apnea syndrome. Am J Respir Crit Care Med 1994;149:416-22.

48. Sun X, Luo J, Xiao Y. Continuous positive airway pressure is associated with a decrease in pulmonary artery pressure in patients with obstructive sleep apnoea: a meta-analysis. Respirology 2014;19:670-4.

49. Atwood Jr CW, McCrory D, Garcia JG, et al. Pulmonary artery hypertension and sleep-disordered breathing: ACCP evidence-based clinical practice guidelines. Chest 2004;126:72S-7S.

50. Dursunoglu N, Dursunoglu D, Kilic M. Impact of obstructive sleep apnea on right ventricular global function: Sleep apnea and myocardial performance index. Respiration 2005;72:278-84.

51. Romero-Corral A, Somers VK, Pellikka PA, et al. Decreased right and left ventricular myocardial performance in obstructive sleep apnea. Chest
2007;132:1863-70.

52. Tugcu A, Guzel D, Yildirimturk O, et al. Evaluation of right ventricular systolic and diastolic function in patients with newly diagnosed obstructive sleep apnea syndrome without hypertension. Cardiology 2009;113:184-92.

53. Verbraecken J, Van de Heyning C, Kerremans M, et al. Echocardiographic and tissue doppler evaluation of cardiac function in obstructive sleep apnea before and after CPAP therapy. Nederlandse vereniging voor Slaap - Waak Onderzoek 2005;16:129-32.

54. Shivalkar B, Van de Heyning C, Kerremans M, et al. Obstructive sleep apnea syndrome: more insights on structural and functional cardiac alterations, and the effects of treatment with continuous positive airway pressure. J Am Coll Cardiol 2006;47:1433-9.

55. Tavil Y, Kanbay A, Sen N, et al. Comparison of right ventricular functions by tissue doppler imaging in patients with obstructive sleep apnea syndrome with or without hypertension. Int J Cardiovasc Imaging 2007;23:469-77.

56. Tugcu A, Yildirimturk O, Tayyareci Y, et al. Evaluation of subclinical right ventricular dysfunction in obstructive sleep apnea patients using velocity vector imaging. Circ J 2010;74:312-9.

57. Hammerstingl C, Schueler R, Wiesen M, et al. Effects of untreated obstructive sleep apnea on left and right ventricular myocardial function. Int J Cardiol 2012;155:465-9.

58. Hoeper MM, Lee SH, Voswinckel R, et al. Complications of right heart catheterization procedures in patients with pulmonary hypertension in experienced centers. J Am Coll Cardiol 2006;48:2546-52.

59. Nathan SD, Barbera JA, Gaine SP, et al. Pulmonary hypertension in chronic lung disease and hypoxia. Eur Respir J 2019;53:1801914.

60. Kolar F, Ostadal B. Right ventricular function in rats with hypoxic pulmonary hypertension. Pflugers Arch 1991;419:121-6.

61. Chaouat A, Weitzenblum E, Kessler R, et al. Fiveyear effects of nasal continuous positive airway pressure in obstructive sleep apnoea syndrome. Eur Respir J 1997;10:2578-82.

62. Arias MA, Garcia-Rio F, Alonso-Fernandez A, et al. Pulmonary hypertension in obstructive sleep apnoea: effects of continuous positive airway pressure: a randomized, controlled cross-over study. Eur Heart J 2006;27:1106-13.

63. Castro-Anon O, Golpe R, Perez-de-Llano LA, et al. Haemodynamic effects of non-invasive ventilation 
in patients with obesity-hypoventilation syndrome. Respirology 2012;17:1269-74.

64. Held M, Walthelm J, Baron S, et al. Functional impact of pulmonary hypertension due to hypoventilation and changes under noninvasive ventilation. Eur Respir J 2014;43:156-65.

65. Masa JF, Corral J, Caballero C, et al. Non-invasive ventilation in obesity hypoventilation syndrome without severe obstructive sleep apnoea. Thorax 2016;71:899-906.

66. Onofri A, Patout M, Kaltsakas G. Neural respiratory drive and cardiac function in patients with obesity hypoventilation syndrome following initiation of noninvasive ventilation. J Thorac Dis 2018;10:S135-43.

67. Suda R, Tanabe N, Terada J et al. Pulmonary hypertension with a low cardiac index requires a higher $\mathrm{PaO} 2$ level to avoid tissue hypoxia. Respirology 2020;25:97-103.

68. Li S, Zhang X, Dong M, et al. Effects of spironolactone in heart failure with preserved ejection fraction: a meta-

Cite this article as: Louise BJ, Carys F, Philip M. Narrative review of sleep and pulmonary hypertension. J Thorac Dis 2020;12(Suppl 2):S191-S201. doi: 10.21037/jtd-cus-2020-004 analysis of randomized controlled trials. Medicine (Baltimore) 2018;97:e11942.

69. Rich S, Seidlitz M, Dodin E, et al. The short-term effects of digoxin in patients with right ventricular dysfunction from pulmonary hypertension. Chest 1998;114:787-92.

70. Ruiter G, Lankhorst S, Boonstra A, et al. Iron deficiency is common in idiopathic pulmonary arterial hypertension. Eur Respir J 2011;37:1386-91.

71. Ruiter G, Lanser IJ, de Man FS, et al. Iron deficiency in systemic sclerosis patients with and without pulmonary hypertension. Rheumatology (Oxford) 2014;53:285-92.

72. Rhodes CJ, Howard LS, Busbridge M, et al. Iron deficiency and raised hepcidin in idiopathic pulmonary arterial hypertension: clinical prevalence, outcomes, and mechanistic insights. J Am Coll Cardiol 2011;58:300-9.

73. Van De Bruaene A, Delcroix M, Pasquet A, et al. Iron deficiency is associated with adverse outcome in Eisenmenger patients. Eur Heart J 2011;32:2790-9. 